\title{
Sea-ice mechanical energy balance: nearshore Chukchi Sea, 1982
}

\author{
ROBERT S. PRITCHARD \\ IceCasting, Inc., 11042 Sand Point Way, N.E., Seattle, WA, U.S.A.
}

\begin{abstract}
The mechanical energy balance of sea ice provides information about ice dynamic behavior, driving forces and the constitutive law. The energy balance equation, formed as the product of ice velocity with the ice momentum balance equation, describes changes to the kinetic and potential energy densities as power is input to the ice by wind and current. The momentum balance equation may also be used to describe the ice-stress divergence, air stress, and water stress, but the scalar form of the energy balance is simpler to understand. This paper provides new interpretations of several terms in the energy balance equation, in particular power input by air and water stress and by sea-surface tilt. Barometric pressure fields and drifting buoys deployed on the Chukchi Sea ice cover during 1982 provide wind, ice motion and current measurements that allow each term in the energy balance equation to be evaluated as a function of time. Magnitudes of power input by wind and current show how the energy balance is decomposed and help describe the relative importance of these driving forces. In the nearshore Chukchi Sea during February, March and April 1982, both wind and current provided significant forcing of the ice. Ice stress was also important and, at times, dominated other terms in the mechanical energy balance.
\end{abstract}

\section{INTRODUCTION}

The purposes of this study are to understand how mechanical energy is transferred from the atmosphere into the ice and ocean by dynamical processes; to understand ice behavior off the northwest coast of Alaska, where the nearshore Chukchi Sea ice is very dynamic and the ice is heavily ridged; and to estimate the relative importance of wind, current, and ice stress on ice motion. This study uses the sea-ice energy balance equation introduced by Coon and Pritchard (1979) as a simple way to understand how power input by wind and current is transferred between the atmosphere, ice and ocean.

Three ARGOS buoys deployed on the Chukchi Sea ice cover about $50 \mathrm{~km}$ offshore between Wainwright and Point Hope in late January 1982 provide data for this study. In addition to transmitting their positions, each buoy contained a current meter tethered $10 \mathrm{~m}$ below the waterline to measure current relative to the drifting buoy. Ice position and relative current estimates were obtained at $6 \mathrm{~h}$ intervals using optimal interpolation, and filtered using a $48 \mathrm{~h}$ cosine bell filter to remove tidal and inertial oscillations. Ice motion showed three general trends. Ice in the central Chukchi Basin (further than about $200 \mathrm{~km}$ from shore) drifted about $650 \mathrm{~km}$ toward the northwest from December 1981 until June 1982. Ice in Hope Basin drifted about $500 \mathrm{~km}$ toward the north-northwest during these six months. Ice nearer to shore between Cape Lisburne and Barrow drifted back-and-forth alongshore, in episodes lasting about ten days, with typical daily dis- placements of 5 to $10 \mathrm{~km}$ and monthly displacements of about $200 \mathrm{~km}$, but accumulating only about $100 \mathrm{~km}$ during the six month period (Pritchard and Hanzlick, 1988). Trajectories of the three buoys are presented in Figure 1 from February through April 1982, when wind and current data are available. Buoys 3623 and 3625 were located near Wainwright and Point Lay, respectively, and buoy 3624 was near Point Hope. All three buoys had similar motions, although buoy 3624 appeared to be affected more by current through the Bering Strait. Buoys 3623 and 3625 provided current measurements from approximately 15 February (Julian day 46) to 1 March (Julian day 60 ), after which the current meters were destroyed by heavy ridging. During the period for which current data are available, these two buoys moved primarily alongshore toward the northeast, with buoy 3623 undergoing two rapid reversals that were about three days apart. Buoy 3624 reported both position and current data from 15 February (Julian day 46) until 1 May (Julian day 121). This buoy exhibited predominantly north-south motions and displayed several reversals. Stick plots of ice velocity, wind, current and relative current histories are presented for each buoy by Pritchard and Hanzlick (1988).

It is generally accepted that Chukchi Sea ice motion is driven primarily by wind (e.g. Aagaard and others, 1985; Kozo and others, 1987). These comparisons of wind and current forcing usually involve a comparison between wind and current velocity, or between forces in the momentum balance. Pritchard and Han- 


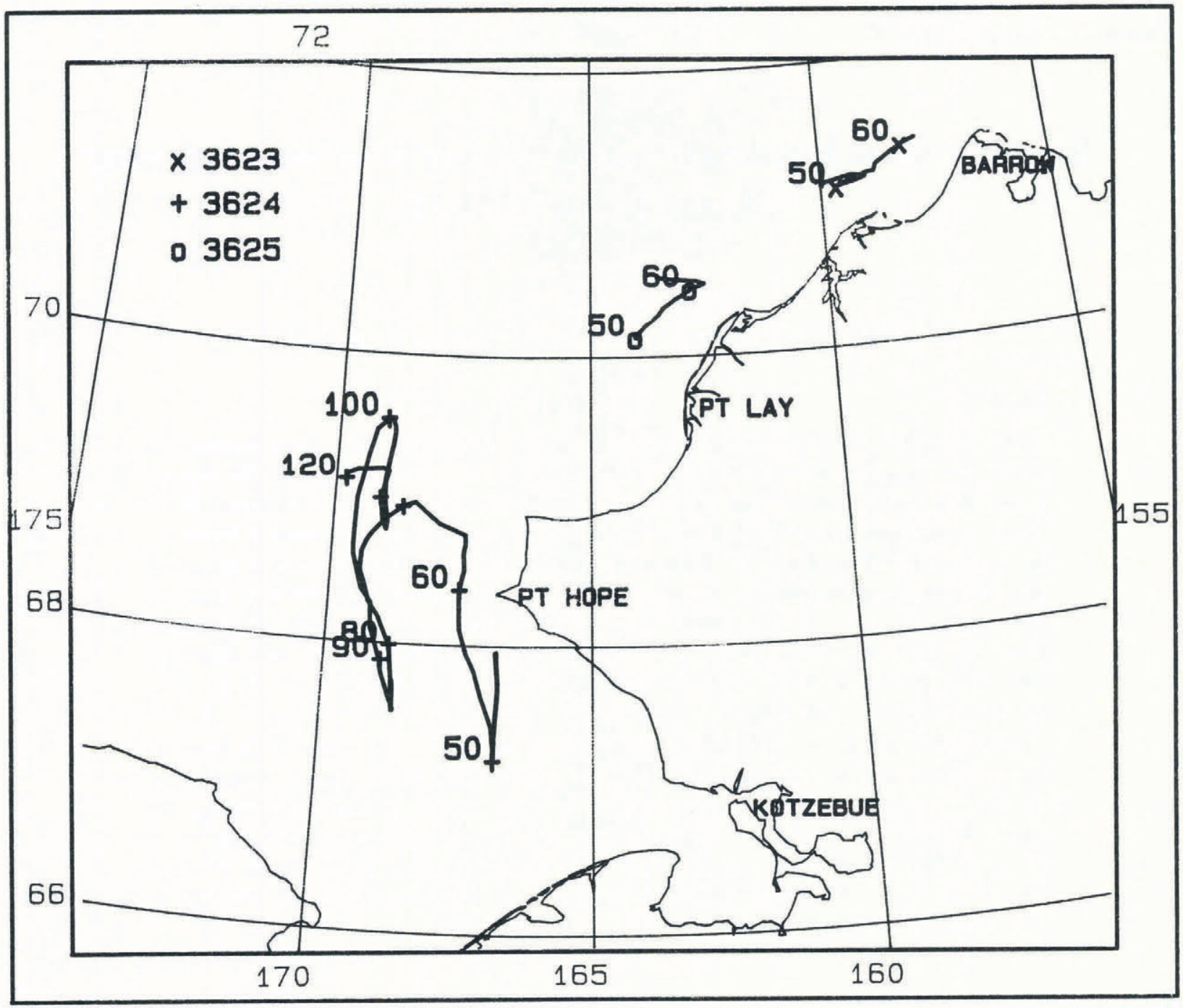

Fig. 1. Trajectories of buoys in nearshore Chukchi Sea, February-April 1982.

zlick (1988) and Pritchard (1988) used the fact that the free-drift ice velocity relative to geostrophic current $\left(\mathbf{v}-\mathbf{c}_{\mathrm{g}}\right)$ is the only velocity term that is wind-driven (e.g. Pritchard, 1984a), and decomposed the ice velocity $\mathbf{v}$ into the sum of this relative velocity and geostrophic current $\mathrm{v}=\left(\mathrm{v}-\mathrm{c}_{\mathrm{g}}\right)+\mathrm{c}_{\mathrm{g}}$. From December 1981 until June 1982 , current described from 44 to $93 \%$ of the ice-velocity variance, depending on location, whereas the wind-driven component described from 0 to $77 \%$. The present study was conducted to learn why different investigators reached different conclusions about the importance of winds and currents in moving the Chukchi Sea ice cover.

\section{MECHANICAL ENERGY BALANCE}

The mechanical energy budget of the sea-ice cover was derived by Coon and Pritchard (1979) by forming an inner product between the ice velocity and the momentum balance equation. This approach is again followed, but several of the terms are redefined and reinterpreted in the light of improved understanding and the notation is changed slightly to conform to more recent ice dynamic models. The momentum balance equation for sea ice is (e.g. Coon and others, 1974; Pritchard, 1981)

$$
m\left(\frac{\mathrm{d} \mathbf{v}}{\mathrm{d} t}+f \mathbf{k} \times \mathbf{v}+g \nabla \eta\right)=A\left(\tau_{\mathrm{a}}+\tau_{\mathrm{w}}\right)+\nabla \cdot \sigma,
$$

where $m$ is mass per unit area of the ice, $\mathbf{v}$ is ice velocity, $f=2 \Omega \sin \phi$ is the Coriolis parameter, $\Omega$ is Earth's rotation rate, $\phi$ is latitude, $\mathrm{k}$ is an upward unit vector, $g$ is acceleration due to gravity, $\eta$ is sea-surface dynamic height, $A$ is ice compactness, $\tau_{\mathrm{a}}$ is air stress, $\tau_{\mathrm{w}}$ is water stress, and $\sigma$ is internal ice stress. The areal mass density $m$ depends on the ice-thickness distribution (Thorndike and others, 1975)

$$
m=\int \rho_{\mathrm{i}} h g(h) \mathrm{d} h,
$$

where $\rho_{\mathrm{i}}$ is ice density, $h$ is thickness, and $g(h)$ is icethickness probability-density distribution. In general, mass density increases or decreases with thermal growth or decay, but the calculations presented here assume a constant thickness distribution, where $m=1.92 \times$ $10^{3} \mathrm{~kg} \mathrm{~m}^{-2}$.

Air stress $\tau_{\mathrm{a}}$ is estimated as a quadratic function of surface wind $\mathrm{U}_{10}$

$$
\tau_{\mathrm{a}}=\rho_{\mathrm{a}} C_{10}\left|\mathbf{U}_{10}\right| \mathbf{U}_{10},
$$


where $\rho_{\mathrm{a}}=1.4 \mathrm{~kg} \mathrm{~m}^{-3}$ is air density and $C_{10}=2 \times 10^{-3}$ is a drag coefficient (Leavitt, 1980). Gradient wind was estimated from National Meteorological Center sea-level pressure data archived at the Pacific Marine Environmental Laboratory (METLIB software, Macklin and others, 1984), multiplied by 0.70 , and turned leftward $30^{\circ}$ to estimate surface wind.

The oceanic mixed-layer is described by a shallow loglayer with linearly increasing eddy viscosity overlying an Ekman layer (McPhee, 1982) and forced at the surface by water stress $\tau_{\mathrm{w}}$. This two-layer model describes the velocity profile as a function of water stress, allowing current beneath the mixed layer to be inferred from the 10 m-deep current measurements (see Appendix A). Water stress $\tau_{\mathrm{w}}$ is a function of ice velocity $\mathrm{v}$ relative to current beneath the mixed layer $c_{g}$, which is assumed to be geostrophic

$$
\tau_{\mathrm{w}}=\tau_{\mathrm{w}}\left(\mathrm{c}_{\mathrm{g}}-\mathrm{v}\right),
$$

where the sign of $c_{g}-v$ is chosen to describe traction acting on the ice, as in Equation (1).

Pre-multiplying all terms in the momentum balance Equation (1) by $\mathbf{v}$ and forming the inner product transforms the tractions and acceleration into power and energy rate terms

$$
\mathbf{v} \cdot m\left(\frac{\mathrm{d} \mathbf{v}}{\mathrm{d} t}+f \mathbf{k} \times \mathbf{v}+g \nabla \eta\right)=\mathbf{v} \cdot A\left(\tau_{\mathrm{a}}+\tau_{\mathrm{w}}\right)+\mathbf{v} \cdot(\nabla \cdot \sigma) .
$$

The inertial acceleration term $\mathbf{v} \cdot m \mathrm{~d} \mathbf{v} / \mathrm{d} t$ is the substantial derivative of kinetic energy density $K=1 / 2 m \mathbf{v} \cdot \mathbf{v}$, which is (e.g. Malvern, 1969)

$$
\dot{K}=m \mathbf{v} \cdot \frac{\mathrm{d} \mathbf{v}}{\mathrm{d} t} .
$$

The Coriolis acceleration term is zero because ice velocity is orthogonal to the Coriolis acceleration. The sea-surface tilt acceleration term $\mathbf{v} \cdot m g \nabla \eta$ is the advective part of the substantial derivative of potential energy density $P=m g \eta$, which is

$$
\dot{P}=m g\left(\eta_{t}+\mathbf{v} \cdot \nabla \eta\right),
$$

where $\eta_{t}$ is the partial time derivative. The advective term contributes to the mechanical energy balance as

$$
p_{\mathrm{g}}=m g \mathbf{v} \cdot \nabla \eta .
$$

The remaining non-steady change of potential energy $m g \eta_{t}$ does not appear in Equation (5); it requires consideration of the ocean energy balance. Although it is about $20 \mathrm{~W} \mathrm{~m}^{-2}$ for a $2 \mathrm{~m}$ thick ice cover raised $10 \mathrm{~cm} \mathrm{~d}^{-1}$, a substantial value, the present analysis is valid because $p_{\mathrm{g}}$ appears in this formulation of the ice mechanical energy balance, not $\mathrm{d} P / \mathrm{d} t$.

Power input by air stress to the ice is

$$
p_{\mathrm{a}}=\mathbf{v} \cdot A \tau_{\mathrm{a}},
$$

where the air stress can be estimated from Equation (3). Power input by water stress on the ice is

$$
p_{\mathrm{w}}=\mathbf{v} \cdot A \tau_{\mathrm{w}},
$$

which is the negative of power input to the ocean. The definition of this term differs from Coon and Pritchard (1979) because the sign is changed and $p_{\mathrm{g}}$ is now identified with changes in potential energy. The effect of ice stress on the energy balance is represented by the rate at which work is done by ice-stress divergence

$$
p_{\mathrm{i}}=-\mathbf{v} \cdot(\nabla \cdot \sigma)
$$

This definition follows Coon and Pritchard (1979), who used $p_{\mathrm{i}}=-p_{\mathrm{f}}+p_{\mathrm{d}}$, where $p_{\mathrm{f}}=\nabla \cdot(\mathbf{v} \cdot \sigma)$ is horizontal stress-flux divergence and $p_{\mathrm{d}}=\operatorname{tr}(\sigma \mathrm{D})$ is the inner product of stress and stretching, D. In this present paper, the analysis is focused on the air and water stress terms and only the total effect of ice stress $p_{\mathrm{i}}$ is estimated. Separation of $p_{\mathrm{i}}$ into $p_{\mathrm{f}}$ and $p_{\mathrm{d}}$ requires that the stress field be determined using a complete ice dynamics model.

Combining all terms defined above provides the energy balance equation

$$
\dot{K}+p_{\mathrm{g}}=p_{\mathrm{a}}+p_{\mathrm{w}}-p_{\mathrm{i}} .
$$

Both kinetic energy and potential energy increase as the atmosphere does work on the upper ice surface, increase as the ocean does work on the ice, and decrease as ice stress dissipates energy by deformation and fluxes energy away by the stress gradient. Power input by the atmosphere $p_{\mathrm{a}}$ and the ocean $p_{\mathrm{w}}$ provide measures of the relative importance of wind and current.

Terms in the energy balance Equation (12) are estimated using a combination of local measurements and models. Wind is estimated from the barometric pressure field, ice motion and current are measured, and ice condition describes compactness and mean thickness. The time history of kinetic energy and its material rate are estimated from knowledge of the buoy velocity history. The potential energy term $p_{\mathrm{g}}$ is estimated assuming that current beneath the mixed layer $\mathrm{c}_{\mathrm{g}}$ is geostrophic

$$
m g \nabla \eta=-m f \mathbf{k} \times \mathbf{c}_{g} .
$$

Power input by air stress $p_{\mathrm{a}}$ and by water stress $p_{\mathrm{w}}$ are estimated using the air and water stress laws, ice velocity, and current. The remaining term $p_{\mathrm{i}}$ cannot be estimated by local measurements because stress depends on deformation, which cannot be determined by a single buoy. However, as the only unknown term in the energy balance, it can be estimated as the remainder in Equation (12). Since time histories of each term are determined, the energy balance equation can also be integrated over any time interval to estimate the accumulated work done on the ice.

Figures 2, 3 and 4 present the observed energy budgets $\left(p_{\mathrm{g}}, p_{\mathrm{a}}, p_{\mathrm{w}}\right.$ and $\left.p_{\mathrm{i}}\right)$ for the three buoys shown in Figure 1. Plots of all variables are presented at the same scale, a compromise chosen to allow a simple comparison between the different contributors to the energy balance, while presenting both the typical variations and the largest storms (which exceed the scale). The maximum value of the kinetic energy term $\mathrm{d} K / \mathrm{d} t$ is negligible compared to all other terms in the energy balance, so it 

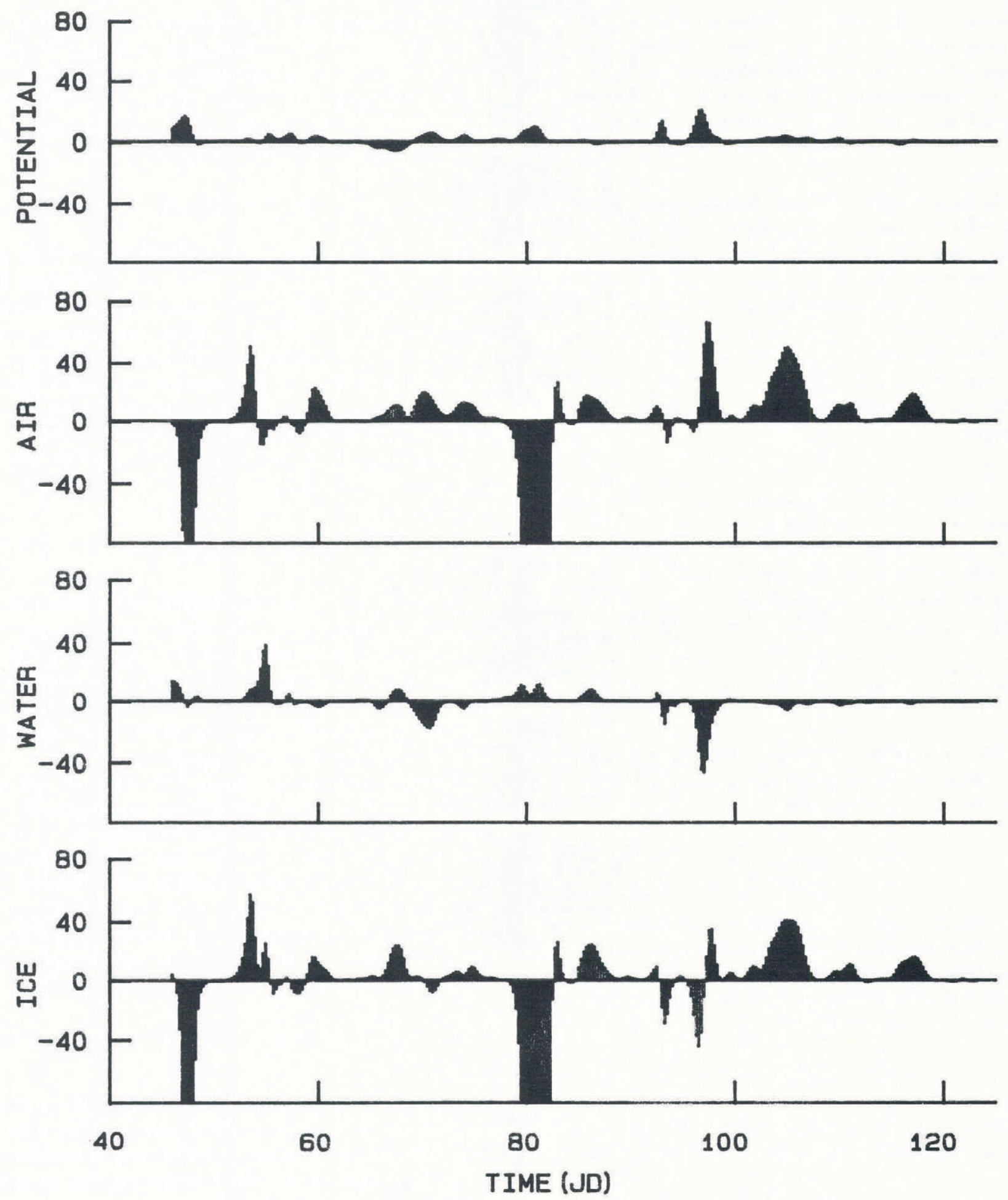

Fig. 2. Mechanical energy balance of buoy 3624. Power terms have units of $m W m^{-2}$. Time is given in day of the year. The four panels, from top to bottom, are: (a) advective part of the substantial derivative of potential energy density $p_{g}$, (b) power input by air stress $p_{a}$, (c) power input by water stress $p_{w}$ and (d) the effect of ice stress $p_{i}$.

is not shown. In these calculations, compact ice is assumed, where $A=1$.

Energy is input by wind in episodes lasting on the order of a few days, which is typical for storm events. Power is input to the ice by wind most frequently in these cases (the positive events), but in two cases (around days 47 and 80 ) extremely large amounts of energy were removed from the ice by wind. During both events, the ice was transported southward by current in opposition to large southerly winds (Pritchard and Hanzlick, 1988).
The events are so big that the cumulative total windenergy integrated over time is roughly $-30 \mathrm{~kJ} \mathrm{~m}^{-2}$ at buoy 3624 . Wind histories at each of the three buoys are different; small at buoys 3623 and 3625 , but significant at buoy 3624 . This difference was not expected because the buoys are only about $150 \mathrm{~km}$ apart. However, since winds were calculated using software that has been tested thoroughly by its developers (Macklin and others, 1984), we can only assume that these are realistic estimates of actual winds. Power input by water 

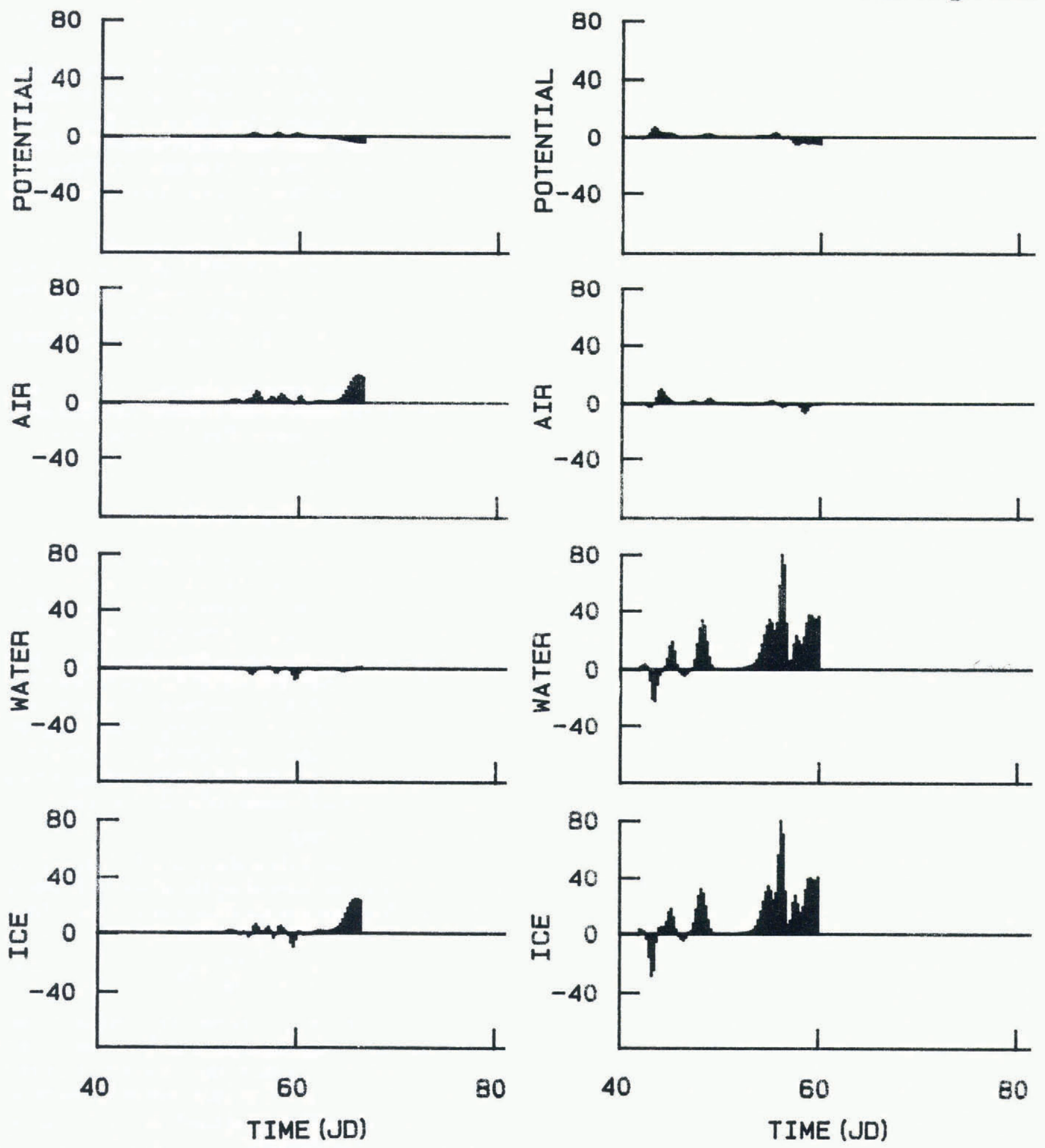

Fig. 3. Mechanical energy balance of buoy 3625. Power terms have units of $m W m^{-2}$. Time is given in day of the year. The four panels, from top to bottom, are: (a) advective part of the substantial derivative of potential energy density $p_{g}$, (b) power input by air stress $p_{a}$, (c) power input by water stress $p_{w}$ and (d) the effect of ice stress $p_{i}$.

stress on the ice is smaller than power input by wind for buoys 3624 and 3625 , but the general characteristics are similar. At buoy 3623, much more power is input by water stress than by air stress. The effect of ice stress $p_{\mathrm{i}}$ at each buoy is similar to power input by air stress, indicating that the stress divergence is important during this period.

The drag coefficient $C_{10}$ affects $p_{\mathrm{a}}$ linearly, and an error in the former introduces the same percentage error into the latter. These changes in $p_{\mathrm{a}}$ introduce equal 
changes to $p_{\mathrm{i}}$, since it is determined as the residual in the energy balance equation.

Although $p_{\mathrm{a}}$ is power input by air stress on the moving ice, and $p_{\mathrm{w}}$ is power input by water stress on the moving ice, these terms do not discriminate between power input by different processes, namely, between forcing by local wind and by current driven by large-scale pressure systems and guided by topography. Since the ice velocity is affected simultaneously by wind and current, both $p_{\mathrm{a}}$ and $p_{\mathrm{w}}$ are affected by all processes. Furthermore, the ice response is strongly non-linear, which makes it impossible to decompose the ice velocity uniquely into terms forced by wind, current and ice stress. However, some guidance has come from re-stating the mechanical energy balance as viewed by an observer moving with the geostrophic current.

\section{WIND AND CURRENT PROCESSES}

If ice behavior was linear, as for Newtonian fluid, solutions could be obtained for each separate forcing function. Lacking this linearity, it is not possible to define unique measures of forcing by wind and current. In pursuit of this goal, however, we rewrite the momentum balance Equation (1) and mechanical energy balance Equation (5) using a reference frame that translates with the geostrophic current while continuing to rotate with the Earth. In the new frame, observed ice velocity is $\mathbf{v}-\mathbf{c}_{\mathrm{g}}$. Assuming all forces and tractions are frame-indifferent, air and water stress and stress divergence are unchanged. Thus, the mechanical energy balance Equation (5) becomes

$$
\begin{aligned}
& \left(\mathbf{v}-\mathbf{c}_{\mathrm{g}}\right) \cdot m\left(\frac{\mathrm{d}\left(\mathbf{v}-\mathbf{c}_{\mathrm{g}}\right)}{\mathrm{d} t}+f \mathbf{k} \times\left(\mathbf{v}-\mathbf{c}_{\mathrm{g}}\right)\right) \\
= & \left(\mathbf{v}-\mathbf{c}_{\mathrm{g}}\right) \cdot A\left(\tau_{\mathrm{a}}+\tau_{\mathrm{w}}\right)+\left(\mathbf{v}-\mathbf{c}_{\mathrm{g}}\right) \cdot(\nabla \cdot \boldsymbol{\sigma}),
\end{aligned}
$$

where sea-surface tilt again is assumed to satisfy Equation (13), and the substantial derivative of $c_{g}$ is neglected. The second term $\left(\mathbf{v}-\mathbf{c}_{\mathrm{g}}\right) \cdot m f \mathbf{k} \times\left(\mathbf{v}-\mathbf{c}_{\mathrm{g}}\right)$ is zero, but has been included for clarity to suggest the form of the momentum balance equation. A word of caution is in order because the geostrophic current field is not necessarily uniform, but it is not meaningful to use a different reference frame at each location. Equation (14) strictly makes sense only in free drift, where ice at a location drifts independently of its neighbors. The new expression provides useful descriptions of several physical processes affected by wind and current, as seen in the next section. As we shall see, neither Equation (5) nor Equation (14) is able to identify all the processes uniquely. Because of this shortcoming, we present only sample data for buoy 3624 in the remainder of this section, rather than the complete set for all three buoys.

\section{Local wind forcing}

To help define terms that describe the power input by local wind forcing, consider free drift, where ice-stress divergence is neglected. Air stress is a known function of the local wind $\mathrm{U}_{10}$, and water stress depends on geostrophic current relative to ice velocity $\mathbf{c}_{\mathrm{g}}-\mathbf{v}_{\mathrm{fd}}$. In free drift, Equation (14) is therefore a relationship between relative velocity and wind velocity $\mathbf{U}_{10}$ (e.g. Pritchard, $1984 \mathrm{~b})$. The free-drift wind power available is

$$
p_{\mathrm{fd}}=\left(\mathrm{v}_{\mathrm{fd}}-\mathrm{c}_{\mathrm{g}}\right) \cdot A \tau_{\mathrm{a}} .
$$

This definition describes the power available only from wind and properly excludes the effect of current advection. Wind moves the ice, which shears the mixed layer, but it does not affect the deep current, as shown in Equation (14). Free-drift power is presented in Figure 5a. This term is roughly proportional to wind speed cubed and, therefore, it varies quickly as wind speed changes. It is non-negative because $\mathbf{v}_{\mathrm{fd}}-\mathbf{c}_{\mathrm{g}}$ and $\mathbf{U}_{10}$ form an acute angle. Comparing Figure 5a with Figure 2 shows that there was far more energy available in the wind than was transferred to the ice by $p_{\mathrm{a}}$, which demonstrates that icestress divergence and/or current effects were important during this period.

Since local winds generate relative velocity in free drift, it seems reasonable to use a similar definition when ice-stress effects are present. Therefore, power input by local wind is defined as

$$
p_{\mathrm{u}}=\left(\mathbf{v}-\mathbf{c}_{\mathrm{g}}\right) \cdot A \boldsymbol{\tau}_{\mathrm{a}} .
$$

This differs from power input by air stress $p_{\mathrm{a}}$ because of advection by the ocean current. Local wind forcing $p_{\mathrm{u}}$ (Fig. $5 \mathrm{~b}$ ) is less than power input by air stress $p_{\mathrm{a}}$ (Fig. 2b), which shows how current influences behavior.

This measure of local wind power is meaningful during free drift. However, if ice-stress divergence holds the ice stationary while wind and current are non-zero, local wind forcing becomes $p_{\mathrm{u}}=-\mathrm{c}_{\mathrm{g}} \cdot \tau_{\mathrm{w}}\left(\mathrm{c}_{\mathrm{g}}\right)$, which suggests that current forcing alone contributes to local wind forcing. This result is nonsensical and, unfortunately, shows that $p_{\mathrm{u}}$ is not an ideal measure of local wind power.

\section{Mixed-layer shearing}

Energy dissipated by vertical shearing of the mixed layer $p_{\mathrm{m}}$ is determined by integrating the product of current velocity gradient and viscous stress over the mixed-layer depth

$$
p_{m}=\int_{-z_{m}}^{-z_{0}} \frac{\mathrm{d} \mathbf{c}}{\mathrm{d} z} \cdot \tau \mathrm{d} z .
$$

Since current velocity appears only as a derivative, the relative current $\mathbf{c}-\mathbf{c}_{\mathrm{g}}$ may replace $\mathbf{c}$. This relative current is the natural variable in the translating reference frame. Integrate by parts, assume viscous stress to be zero at the bottom of the mixed layer, and assume ice velocity equals surface current $\mathbf{v}=\mathbf{c}_{0}$ at the interface depth $z_{0}$ (see Appendix for the mixed-layer model). Then, since the viscous stress gradient is orthogonal to relative current velocity (Equation (24)), power dissipated by the mixed layer is

$$
p_{\mathrm{m}}=\left(\mathbf{v}-\mathbf{c}_{\mathrm{g}}\right) \cdot A\left(-\boldsymbol{\tau}_{\mathrm{w}}\right),
$$

which is a non-negative function of the relative velocity. The minus sign appears because $-\boldsymbol{\tau}_{\mathrm{w}}$ is traction acting on the ocean. Dissipation by mixed-layer shearing is power input by water stress on ice moving relative to geostrophic current, as seen by an observer moving with the translating reference frame.

Mixed-layer shearing dissipation, shown in Figure 5, has a moderate magnitude. These values depend only on the current relative to ice velocity. The large difference 

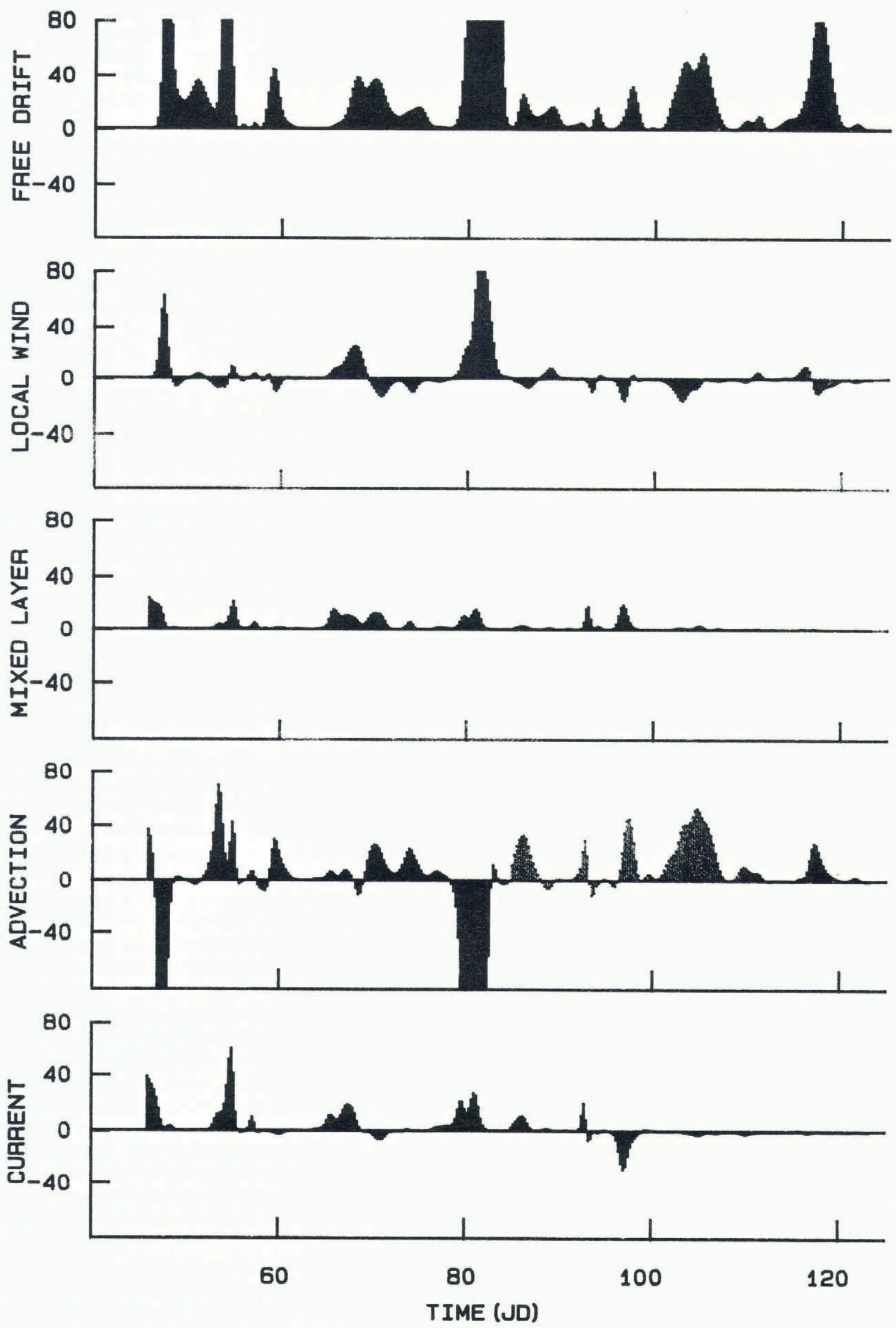

Fig. 5. Alternate mechanical energy balance terms for buoy 3624: (a) power input by air stress in free drift $p_{f d}$, (b) power input by local wind $p_{u}$, (c) power dissipated by mixed-layer shearing $p_{m}$, (d) power input by current advection of air and water stress $p_{\mathrm{c}}$, and (e) power input by current advection of water stress $p_{o}$. 
between power available in free drift and dissipated by mixed-layer shearing shows the importance of ice-stress divergence because these two measures are equal in free drift.

Measurements of current from meters tethered under drifting sea ice are generally thought to be inaccurate, because the relative current $\mathbf{c}-\mathbf{v}$ is often small and current meters have a threshold on the order of $3 \mathrm{~cm} \mathrm{~s}^{-1}$. Mixed-layer shearing dissipation at this threshold is less than $0.2 \mathrm{~m} \mathrm{~W} \mathrm{~m}^{-2}$. Estimates of both relative current and absolute current, determined as $\mathbf{c}=(\mathbf{c}-\mathbf{v})+\mathbf{v}$, are adequate for this study. When relative current is too small to be estimated, then its effect is small, and any correction to $\mathbf{v}$ is negligible. When ice velocity is small and absolute current is also small, then estimates of direction are likely to be in error, but this error is unimportant because current is then small. When relative current is large, absolute current is estimated accurately. Relative current affects $p_{\mathrm{m}}$ roughly as a cubic function, and an error in the former introduces three times the percentage error into the latter. These changes in $p_{\mathrm{m}}$ introduce equal changes to $p_{\mathrm{i}}$.

\section{ALTERNATE ENERGY FORMULATIONS}

The mechanical energy balance referred to the translating frame Equation (14) provides a natural way to define local wind power and mixed-layer shearing dissipation, but it is more useful to introduce these terms into the basic mechanical energy balance Equation (5), replacing Equation (12) with terms that better describe wind and current forcing. To this end, introduce power input by local wind $p_{\mathrm{u}}$ and power dissipated by mixed-layer shearing $p_{\mathrm{m}}$, and the mechanical energy balance becomes

$$
\dot{K}+p_{\mathrm{g}}=p_{\mathrm{u}}-p_{\mathrm{m}}+p_{\mathrm{c}}-p_{\mathrm{i}},
$$

where the remaining term is power input by current advection of air and water stress

$$
p_{\mathrm{c}}=\mathbf{c}_{\mathrm{g}} \cdot A\left(\boldsymbol{\tau}_{\mathrm{a}}+\boldsymbol{\tau}_{\mathrm{w}}\right) \text {. }
$$

Power input by total advection by current $p_{\mathrm{c}}$, shown in Figure $5 \mathrm{~d}$, is quite similar to power input by air stress $p_{\mathrm{a}}$, which suggests that ice velocity is nearly equal to current, making water stress small.

Earlier, $p_{\mathrm{u}}$ was shown to describe free drift well, but to be inadequate to describe fast-ice conditions. As a compromise, re-introduce power input by wind stress $p_{\text {a }}$ instead of $p_{\mathrm{u}}$, because $p_{\mathrm{a}}$ correctly describes power input by wind even though it is affected by both wind and current. The mechanical energy balance then becomes

$$
\dot{K}+p_{\mathrm{g}}=p_{\mathrm{a}}-p_{\mathrm{m}}+p_{\mathrm{o}}-p_{\mathrm{i}},
$$

where the remaining term is power input by current advection of water stress

$$
p_{\mathrm{o}}=\mathrm{c}_{\mathrm{g}} \cdot A \tau_{\mathrm{w}}
$$

Power input by ocean advection $p_{\mathrm{o}}$, shown in Figure 5e, is also similar to power input by water stress, which supports the observations that ice velocity and current are nearly equal. This ocean advection term provides a measure of power input to the ocean system by current that may be independent of local wind-driven effects. This formulation appears to be a reasonable way to decompose wind and current forcing, even though it seems arbitrary to consider only advection of water stress, rather than both air and water stress, but either of these expressions of mechanical energy balance would have more physical meaning if defined from the mechanical energy balance of an ocean dynamics model.

It is worthwhile to reconsider the two extreme conditions: free drift and fast ice. During free drift, power is input by air stress $p_{\mathrm{o}}$, and energy is dissipated by mixedlayer shearing $p_{\mathrm{m}}$. Although $p_{\mathrm{a}}$ is not power input by local wind $p_{\mathrm{u}}$, it is the measure of actual power input by wind forcing as the ice moves. Under fast-ice conditions, power input by air stress $p_{\mathrm{a}}$ is zero, power is input by current moving the ice (relative to the observer moving with the current) $p_{\mathrm{o}}$, and energy is dissipated by mixed-layer shearing $p_{\mathrm{m}}$. Under both of these extreme conditions, the energy balance given by Equation (21) appears to be reasonable. Neither $p_{\mathrm{a}}$ nor $p_{\mathrm{u}}$ is an entirely satisfactory measure of power input by local wind, however, because each can be affected by current forcing. The large difference between $p_{\mathrm{a}}$ and $p_{\mathrm{u}}$ does show, however, that current forcing contributed substantially to the energy balance in the nearshore Chukchi Sea.

\section{CONCLUSION}

This study extends the work of Coon and Pritchard (1979). Several terms in the mechanical energy balance equation are reinterpreted, and a new way to use ice-motion observations directly to estimate the energy budget is presented. The energy terms are easier to understand than the time-varying two-dimensional fields of velocity, deformation, stress and ice condition, with their multiple components. They are scalar variables, formed as combinations of two vectors (four pieces of information collapsed into one). This simplicity is a strength, but the reduced amount of information requires that we look into other variables to help explain the behavior. Thus, energy studies are helpful, but complement rather than replace studies of force and velocity.

The present study uses buoy data exclusively to estimate all terms in the mechanical energy balance, and estimates the effect of ice stress as a remainder in the equation. An alternative approach is to perform an ice dynamics simulation, and to determine each term in the mechanical energy balance from velocity, stress, current and ice-condition fields simulated by the model. This approach has the advantage that both stress and deformation are determined, making it possible to determine how much of the ice-stress effect is dissipated locally and how much is transferred to other locations by stress-flux divergence.

A unique set of terms has not been found to isolate forcing by wind and current. Three sets have been introduced; each appears to have some value but none is ideal. A full ocean model (perhaps a simple barotropic model) is needed to separate the effects of wind and current. We have learned, however, that both current and wind play important roles in forcing the Chukchi Sea ice. 
It is possible to separate the part of the current $\mathbf{c}_{\mathrm{g}}$ that is correlated with local winds from the remainder and to decompose the energy balance in this way. However, it is unclear if the ice velocity should be similarly decomposed because of the non-linear behavior of the ice.

These energetics arguments can be applied in other regions, and for other purposes, e.g. during CEAREX in the eastern Arctic and northern Barents Sea, and for the purpose of developing models to help understand and forecast noise generated by sea ice (Pritchard, 1984a, 1990).

\section{ACKNOWLEDGEMENTS}

This study was supported by the Office of Naval Research, Arctic Sciences Program, under contract N0001488-C-0580, to improve our understanding of the energy transfer processes in the air-ice-ocean and of the relationship between the dissipation of energy by sea ice and observed ambient noise. I thank T.B. Curtin for his support. I thank K.L. Hammond for editorial services and K. Hutter for a careful review that forced me to pursue a more general formulation.

\section{REFERENCES}

Aagaard, K., A. T. Roach, and J.D. Schumacher. 1985. On the wind-driven variability of the flow through Bering Strait. J. Geophys. Res., 90(C7), 7213-7221.

Coon, M.D. and R.S. Pritchard. 1979. Mechanical energy considerations in sea-ice dynamics. J. Glaciol., 24(90), 377-389.

Coon, M.D., G.A. Maykut, R.S. Pritchard, D.A. Rothrock, and A.S. Thorndike. 1974. Modeling the pack ice as an elastic-plastic material. AIDJEX Bull. 24, 1-105.

Kozo, T.L., W. J. Stringer, and L. J. Torgerson. 1987. Mesoscale nowcasting of sea ice movement through the Bering Strait with a description of major driving forces. Mon. Weather Res. 115, 193-207.

Leavitt, E. 1980. Surface-based air stress measurements made during AIDJEX. In Pritchard, R.S., ed. Sea ice processes and models. Seattle, WA, University of Washington Press, 419-429.

Macklin, S.A., R.L. Brown, J. Gray, and R.W. Lindsay. 1984. METLIB II - a program library for calculation and plotting atmospheric and oceanic profiles. Seattle, National Oceanic and Atmospheric Administration. (Technical Memorandum ERL PMEL54.)

McPhee, M.G. 1982. Sea ice drag laws and simple boundary layer concepts, including application to rapid melting. CRREL Rep. 82-4.

Malvern, L.E. 1969. Introduction to the mechanics of a continuous medium. Engelwood Cliffs, NJ, PrenticeHall.

Pritchard, R.S. 1981. Mechanical behavior of sea ice. In Selvadurai, A.P.S., ed. Mechanical behaviour of structured media. Part A. Amsterdam, Elsevier, 371-405.

Pritchard, R.S. 1984a. Arctic Ocean background noise caused by ridging of sea ice. J. Acoust. Soc. Am., 75(2), 419-427.
Pritchard, R.S. 1984b. Beaufort Sea ice motions. In Barnes, P.W., D.M. Schell, and E. Reimnitz, eds. The Alaskan Beaufort Sea, ecosystems and environments. Orlando, FL, Academic Press, 95-113.

Pritchard, R.S. 1988. Norton Sound and northeastern Bering Sea ice behavior: 1981-1982. In Sodhi, D.S., C.H. Luk, and N.K. Sinha, eds. OMAE 1988 Houston. Proceedings of the Seventh International Conference on Offshore Mechanics and Arctic Engineering. Vol. IV. Arctic engineering and technology. New York, American Society of Mechanical Engineers, 69-74.

Pritchard, R.S. 1990. Sea ice noise-generating processes. J. Acoust. Soc. Am., 88(6), 2830-2842.

Pritchard, R. S. and D. J. Hanzlick. 1988. Chukchi Sea ice motion 1981-82. In Sackinger, W.M. and M.O. Jeffries, eds. Port and Ocean engineering under Arctic Conditions. Vol. III. Fairbanks, AK, University of Alaska. Geophysical Institute, 255-270.

Thorndike, A.S., D.A. Rothrock, G.A. Maykut, and R. Colony. 1975. The thickness distribution of sea ice. J. Geophys. Res., 80(33), 4501-4513.

The accuracy of references in the text and in this list is the responsibility of the author, to whom queries should be addressed.

\section{APPENDIX A}

\section{OCEAN MIXED-LAYER MODEL}

The oceanic mixed-layer model assumes a shallow loglayer with linearly increasing eddy viscosity and constant stress, overlying an Ekman layer (McPhee, 1982). This model was introduced originally in a complex number representation, which is retained for simplicity. Throughout this appendix, boldface type variables represent complex numbers, and the same symbols with absolute values represent the magnitude of the complex number. Momentum balance of the ice, however, with its internal ice-stress divergence term, must be presented as a tensor equation.

Water stress applied by ice on the ocean surface $\tau_{0}$ $=-\tau_{\mathrm{w}}$, the negative of water stress applied by the ocean on the $i c e$, is the viscous stress at the water-ice surface $z_{0}, \quad \tau_{0}=\boldsymbol{\tau}\left(z_{0}\right)$. Friction velocity $\mathbf{u}_{*}$ is aligned with the water stress $\tau_{0}$ and has magnitude equal to the square root of its magnitude

$$
\mathbf{u}_{*}=\left(\frac{\left|\tau_{0}\right|}{\rho_{\mathrm{w}}}\right)^{-1 / 2} \frac{\tau_{0}}{\rho_{\mathrm{w}}} .
$$

Current $\mathbf{c}_{0}=\mathbf{c}\left(z_{0}\right)$ at some small depth, $z_{0}=8.5 \mathrm{~cm}$, equals ice velocity $\mathbf{v}$. The momentum balance and viscous stress laws are

$$
\begin{gathered}
i \rho_{\mathrm{w}} f\left(\mathbf{c}-\mathbf{c}_{\mathrm{g}}\right)=\frac{\mathrm{d} \boldsymbol{\tau}}{\mathrm{d} z}, \\
\tau=K \frac{\mathrm{d} \mathbf{c}}{\mathrm{d} z},
\end{gathered}
$$

where $i=(-1)^{1 / 2}$, c is current velocity at depth $z$ 
(measured positive upward), $\mathbf{c}_{\mathrm{g}}$ is geostrophic current, and $\tau$ is the horizontal component of viscous stress. Eddy viscosity $K$ increases linearly in the upper layer $z_{0}<-z<z_{N}$, remains constant in the lower layer $-z>z_{\mathrm{N}}$ and varies linearly with friction velocity

$$
K=\rho_{\mathrm{w}} k\left|\mathbf{u}_{*}\right| \min \left(-z, z_{\mathrm{N}}\right)
$$

Depth of the lower layer $z_{\mathrm{N}}=\left|\mathbf{u}_{*}\right| \xi_{\mathrm{N}} / f$, where $\xi_{\mathrm{N}}=$ 0.045 is a non-dimensional constant (McPhee, 1982), and $k=0.4$ is the von Karman constant. This formulation assumes that motion is steady, the Coriolis force balances the horizontal pressure-gradient force, and horizontal viscous effects are negligible.

In the lower layer, the constant eddy viscosity produces a classical Ekman layer. Simultaneous solution of the momentum balance and viscous-stress law give the current velocity and viscous-stress profiles

$$
\begin{aligned}
\mathbf{c}-\mathbf{c}_{g} & =-\frac{i \delta \boldsymbol{\tau}_{\mathrm{E}}}{\rho_{\mathrm{w}}\left|\mathbf{u}_{*}\right|} \exp \left[\delta f\left(z+z_{\mathrm{N}}\right) /\left|\mathbf{u}_{*}\right|\right] \\
\boldsymbol{\tau}(z) & =\boldsymbol{\tau}_{\mathrm{E}} \exp \left[\delta f\left(z+z_{\mathrm{N}}\right) /\left|\mathbf{u}_{*}\right|\right] .
\end{aligned}
$$

The complex coefficient $\delta=\left(2 k \xi_{\mathrm{N}}\right)^{-1 / 2}(1+i)$ describes both decay and rotation of the current vector with depth from the interface $-z=z_{\mathrm{N}}$.

In the surface layer, where eddy viscosity is linear, turbulent stress is assumed constant for the purpose of determining current. Under these assumptions, integration of the viscous stress law gives the current profile

$$
\mathbf{c}_{0}-\mathbf{c}=\frac{\tau_{0}}{\rho_{\mathbf{w}}\left|\mathbf{u}_{*}\right| k} \ln \left(-z / z_{0}\right),
$$

where $\mathbf{c}_{0}=\mathbf{c}\left(z_{0}\right)$ is current at the surface. Integrating the momentum equation across the surface layer, this velocity profile gives

$$
\begin{aligned}
& {\left[1+\frac{\delta f}{\left|\mathbf{u}_{*}\right|}\left(z_{\mathrm{N}}-z_{0}\right)\right] \boldsymbol{\tau}_{\mathrm{E}} } \\
= & \tau_{0}\left(1+\frac{i f}{k\left|\mathbf{u}_{*}\right|}\left[\left(z_{\mathrm{N}}-z_{0}\right)-z_{0} \ln \left(z_{\mathrm{N}} / z_{0}\right)\right]\right) .
\end{aligned}
$$

If water stress is specified, Equation (23) can be solved algebraically for $\mathbf{u}_{*}$, Equation (29) for $\boldsymbol{\tau}_{\mathrm{E}}$, and Equations (27) and (28) for $\mathbf{c}-\mathbf{c}_{\mathrm{g}}$ at any depth. If the ice velocity relative to the deep current $\mathbf{v}-\mathbf{c}_{\mathrm{g}}$ is specified, non-linearities require that the equations be solved numerically. 